\title{
CONTROL OF VIBRATION THROUGH AN INNOVATIVE ISOLATION TECHNIQUE OF A MULTISTORY BUILDING USING MAGNETIC FIELD
}

\author{
Arjun Sil \\ Assistant Professor, Dept. of Civil Engineering, NIT Silchar, Assam, India, 788010, silarjun@gmail.com
}

\begin{abstract}
The paper presents a simple and an innovative idea regarding vibration isolation technique of a multistory building using magnetic field and is proposed to application in the field of civil engineering structures. This idea is fully based on hypothetical concept, but the objective is to explore this idea or concept in to the entire community which may be a potential sector for the effective vibration isolation system. The technique is described based on the magnetic properties of materials and a magnetic field characteristic which depends on the amount of current flow, number of turns in coil, distance between electromagnet and the magnetic materials. Therefore using magnetic field, the attraction induced between magnet and magnetic materials, a force could finally be developed on the floor of building. This force would become effective until and unless the power is cutoff. Therefore this induced force is actually acts as a live load on the structure which indirectly increases the weight and this has been described in this paper.
\end{abstract}

Keywords: - Isolation, vibration, frequency, magnetic field, performance based design, damping $* * *$

\section{INTRODUCTION}

Vibration isolation is a way of controlling vibration by modifying the transmission path between the source of excitation and the vibrating structure by introducing specifically design structural elements or in other words, it is a term that is used to describe the response of a vibration isolation system. Literally, transmissibility is the ratio of displacement of an isolated system to the input displacement. It is used to describe the effectiveness of a vibration isolation system. Transmissibility varies with frequency. The isolation systems will actually amplify as opposed to isolate. In a passive system, at frequencies less than its system resonance, no isolation takes place, and ground vibrations are transferred directly through the isolation system (Chopra 2007). At the resonance, amplification occurs, and the transmissibility is greater than unity. Once past or exceeding the resonant frequency, isolation occurs. As one moves further out on the transmissibility curve, the transmissibility approaches zero. So the design of these elements depends upon not only on the dynamic properties of the structure being isolated but also on the nature of excitation. In this evaluation, a multistory building has been considered hypothetically. The aim of this work is to reduce the vibration in this system using magnetic field background. For its effective application, a new inventive mechanism can be applied.

\section{DYNAMIC ANALYSIS AND EVALUATION}

From the background of transmissibility of force and vibration isolation, we can begin by writing the equation of motion:-

$$
[M]\left\{u^{\prime \prime}\right\}+[C]\left\{u^{\prime}\right\}+[K]\{u\}=P(t)
$$

Where $[\mathrm{M}],[\mathrm{C}],[\mathrm{K}]$ are the mass, damping \& stiffness of the system.

The solution of equation is

$$
u(t)=u \sin (w t-\theta)
$$

And transmissibility $(\mathrm{TR})=$ (part of force transmitted/actual force).

Now after solving the above equation we can write the equation of transmissibility in the following way:-

$$
\mathrm{TR}=\sqrt{\left\{\left(1+(2 \mathrm{xn})^{2} /\left(\left(1-n^{2}\right)^{2}+(2 \mathrm{xn})^{2}\right)\right.\right.}
$$

Where ' $\mathrm{x}$, is damping ratio \& ' $\mathrm{n}$, tuning ratio or frequency ratio of the system.Now, a graph has been plotted with TR vs. $\mathrm{n}$ under different damping ratios, which is as:- 


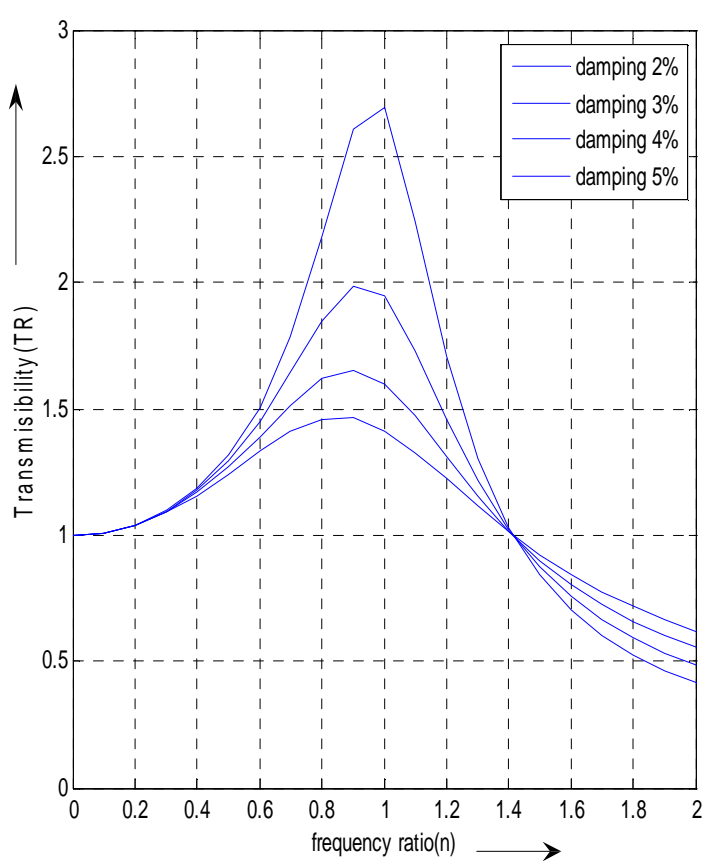

Fig1. Shows Transmissibility (TR) vs. frequency ratio (n) under different amount of damping

And from the graphical analysis of equation (3).we could see that

1. For $(n<1.4142)$ the $T R$ is greater than unity or $(\mathrm{TR}>1)$ so $\mathrm{TR}$ can be reduced by increasing damping

2. For $(\mathrm{n}=1.4142)$ the $\mathrm{TR}$ is equal to unity $(\mathrm{TR}=1)$ and for any value of damping ratios, so in this situation same amount of force will be transmitted.

3. For $(n>1.4142)$ the TR is less than unity or $(T R<1)$ and in this case TR can be reduced by reducing damping.

From the analysis of TR or vibration isolation equation it is found that for $n>1.4142$ the exciting frequency will be at least $41.42 \%$ higher than the natural frequency. So, to achieve desirable isolation i.e. $(\mathrm{n}>1.4142)$ which indicates the zone of effective isolation for any vibrating structures for minimum amount of damping. We have also seen that for steel structures stiffness is less and as well as static/dynamic deformation is more for a particular force. If stiffness is less, the natural frequency will be reduced for a particular mass and the frequency ratio (n) will be higher for a particular excitation frequency. But for RC structures, stiffness is higher compared to steel and static deformation is less for a particular amount of force and natural frequency will be more. Therefore, the frequency ratio (n) will be decreased. In RC structures, both stiffness and mass are higher than steel, therefore due to the variation in exciting frequency, the natural frequency is almost remain same for a particular mass and stiffness. So, we conclude that for a particular location or site for same amount of excitation, the frequency ratio (n) will differ due to different materials properties of structures. To obtain effective vibration isolation of RC structures, it is important to modify such properties so that the structure can be more effective in vibration isolation.

Now aim is to use the zone which is $(\mathrm{n}>1.4142)$ more effective for isolation, and it can be achievable by increasing mass of the system, so in this condition natural frequency of this system will definitely reduced to a minimum level, and then " $n$,or frequency ratio will increase for a particular exciting frequency. After increasing frequency ratio (n) such that it is greater than 1.4142 , then the TR will be less than unity. Therefore by simply increasing mass, TR can be reduced. But in case of earthquake, excitation frequency is a function of the mass of the structure. So without changing the mass, my objective is to modify the lump weight (say=W) by changing $g$ (acceleration due to gravity) for the same mass of the structure.

\section{BASIC CONCEPT}

So to achieve objective, it is necessary to apply a magnetic field on the structure/building in such a way, which will increase the value of ' $g$ ' to the desired level.

Mathematically, it can be written as:-

$$
\mathrm{W}=[\mathrm{w} 1+\mathrm{w} 2]=\left[\mathrm{m} 1 \mathrm{~g}_{\mathrm{e}}+\mathrm{m} 2\left(\mathrm{~g}_{\mathrm{e}}+\mathrm{g}_{\mathrm{m}}\right)\right]
$$

Where $\mathrm{m} 1=$ mass of structure.

$\mathrm{g}_{\mathrm{e}}=$ acceleration due to gravity.

$\mathrm{m} 2$ = mass of magnetic material.

$\mathrm{g}_{\mathrm{m}}=$ magnetic field of attraction.

w1 $1=$ wt.of structure

w2 $=$ wt. of magnetic material.

In the above equation, 'w1' is fixed and ' $w 2$ ' can vary under the influence of magnetic field or magnetic force and if magnetic field increase the w 2 will be naturally increase, so in this case the structure will be more stable under the influence of external excitation. Again mathematically, it can also be written as $\mathrm{w} 2=\mathrm{F}$ (magnetic field or force of attraction between to materials) and from the laws of. Attraction (gravitation + magnetic) between two materials we have

$$
\begin{aligned}
& \left.\mathrm{F}=(\mathrm{Gm} 1 \mathrm{~m} 2) / \mathrm{d}^{2} \quad \text { (gravitational laws }\right) \\
& \mathrm{F}=\left(\mathrm{q}^{*} \mathrm{~m} 1 * \mathrm{~m} 2\right) / \mathrm{d}^{2} \quad(\text { coulomb laws })
\end{aligned}
$$

Therefore the expression of natural frequency $(\omega)$ can be written as:-

$$
\omega=\sqrt{ } \mathrm{Kg} /(\mathrm{mg}+\mathrm{F})
$$


In this evaluation, both formulas are applicable for analysis of static as well as dynamic case. In the above case of gravitational law analysis, it is found that to achieve maximum force $(F)$ either ' $\mathrm{m} 1$ ' or ' $\mathrm{m} 2$ ' should be increased. If we assume that ' $\mathrm{m} 1$ ' is the weight of upper floor of building and ' $\mathrm{m} 2$ ' is weight of base floor of the building, but for earthquake point of view only ' $\mathrm{m} 2$ ' should be increased for stability. Therefore, it also depends on the type of foundation. So, it is better to use raft foundation or rigid base of ground to increase $\mathrm{m} 2$.and also use heavy wt or denser materials to increase the value of ' $F$ '. For the analysis of magnetic field using coulomb law, it is found that magnetic attraction is inversely proportional to the square of the distance, so setup design has

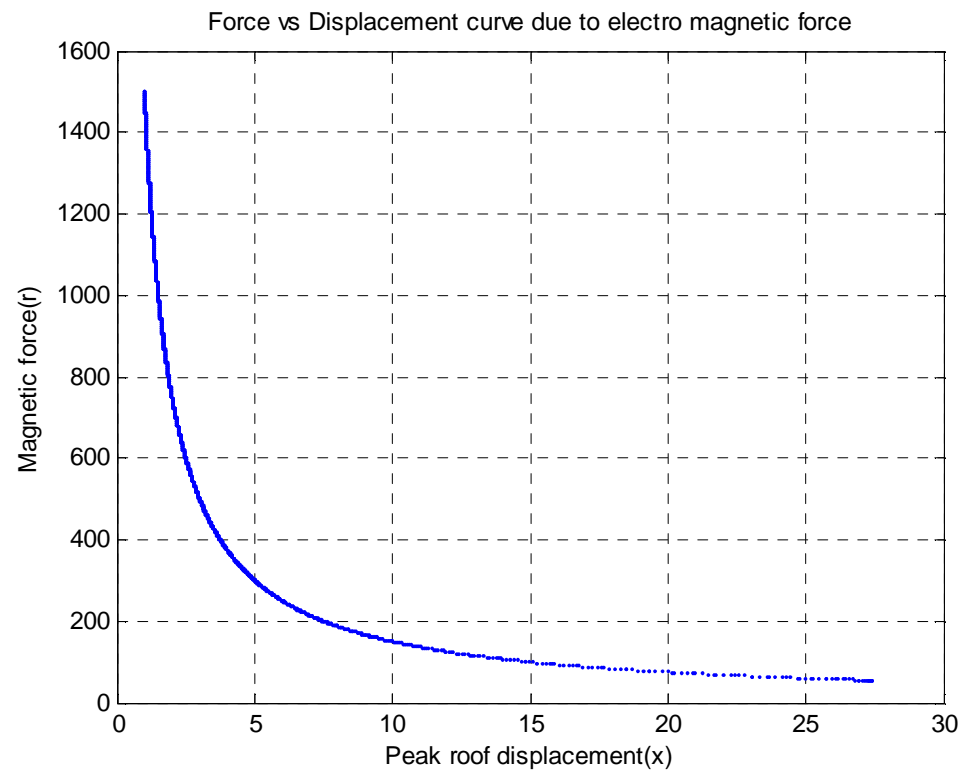

Fig. 2

In this graph, it is seen that magnetic force is inversely proportional to the lateral displacement. or we can say that due to the influence of Magnetic force the lateral displacement $\left(\boldsymbol{\Delta}_{\mathrm{d}}\right.$ ) decreases.

Again we have seen that the Earthquake force $\left(\mathrm{F}_{\mathrm{EQ}}\right)$ or lateral force is directly proportional

to the lateral displacement $\left(\boldsymbol{\Delta}_{\mathbf{d}}\right)$ which can be represented in the following way:-

$$
\mathrm{F}_{\mathrm{EQ} \infty} \Delta_{\mathbf{d}}
$$

Therefore from equation (6) and (7) we get the resultant force ' $R$, which is expressed as (Fig-3):- to be move closer in such a way that the attraction is found maximum between the magnet and magnetic materials.

\section{PROBLEM FORMULATION TECHNIQUES}

The objective is to minimize the lateral displacement $\left(\boldsymbol{\Delta}_{\mathrm{d}}\right)$ using magnetic force $\left(\mathrm{F}_{\mathrm{m}}\right)$ against the higher intensities of Earthquake and develop more stability of the structure. The relationship between the lateral displacement and magnetic force can be represented by graphical form (Fig-2) which is as follows:-

$$
F_{\mathrm{m}} \infty 1 / \Delta_{\mathbf{d}}
$$

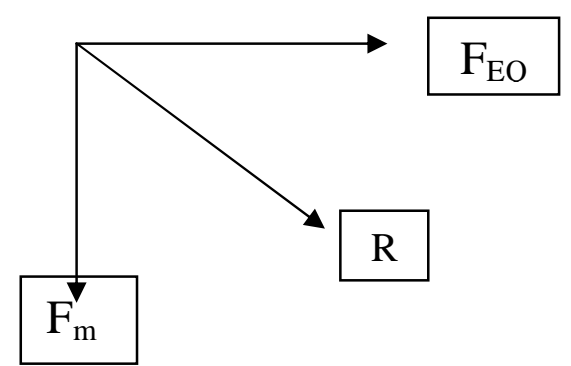

Fig. 3

$$
\mathrm{R}=\sqrt{\left(\mathrm{F}_{\mathrm{EQ}}\right)^{2}+\left(\mathrm{F}_{\mathrm{m}}\right)^{2}}
$$

Now we have,

$$
\begin{gathered}
\mathrm{F}_{\mathrm{EQ}} \Delta_{\mathrm{d}} \\
\mathrm{F}_{\mathrm{EQ}}=\mathrm{k}_{\mathrm{q}} \Delta_{\mathrm{d}} \\
\mathrm{F}_{\mathrm{m}} \propto 1 / \Delta_{\mathrm{d}} \\
\mathrm{F}_{\mathrm{m}}=\mathrm{k}_{\mathrm{m}} / \Delta_{\mathrm{d}} \\
\text { or, } \\
\mathrm{F}_{\mathrm{EQ}}=\mathrm{k}_{\mathrm{q}} \mathrm{k}_{\mathrm{m}} / \mathrm{F}_{\mathrm{m}}
\end{gathered}
$$


Let, $\left(\mathrm{K}=\mathrm{k}_{\mathrm{m}} \mathrm{k}_{\mathrm{q}}\right)$

$$
\mathrm{F}_{\mathrm{EQ}}=\mathrm{K} / \mathrm{F}_{\mathrm{m}}
$$

Where $\mathrm{K}=$ is a constant and can be called as composite stiffness.

From equation (11) it is seen that as the magnetic force increases, the effect or severity of the Earthquake force $\left(\mathrm{F}_{\mathrm{EQ}}\right)$ reduces and the stiffness of the structure increases in the form of composite effective stiffness $(\mathrm{K})$ with ' $\mathrm{k}_{\mathrm{m}}$ '.

A graph has been plotted (K vs. R) as follows (Fig-4):

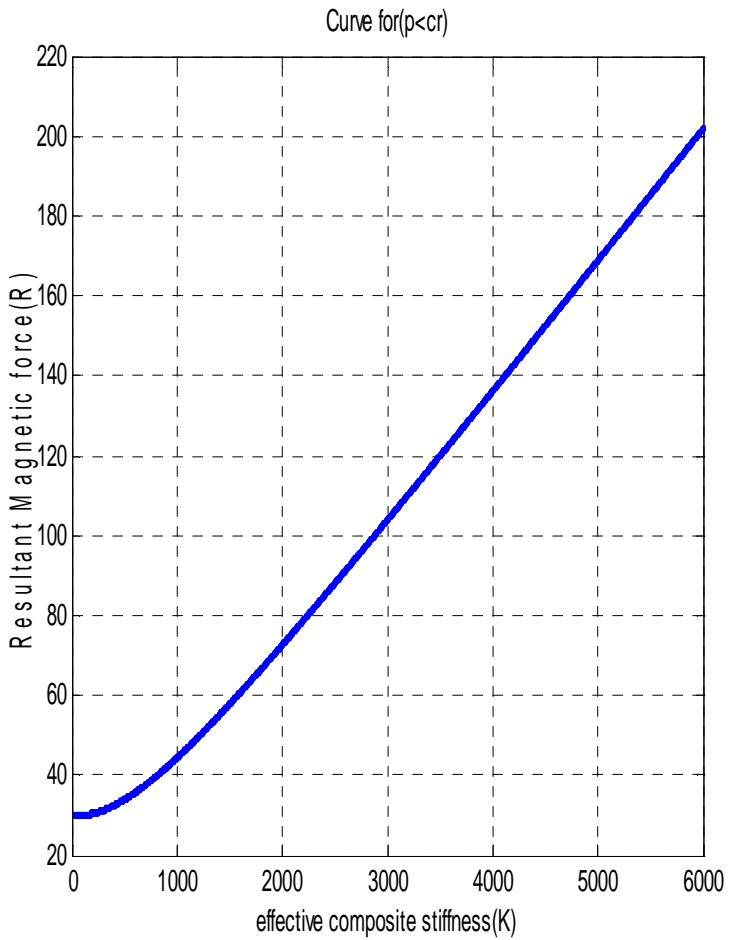

Fig:-4

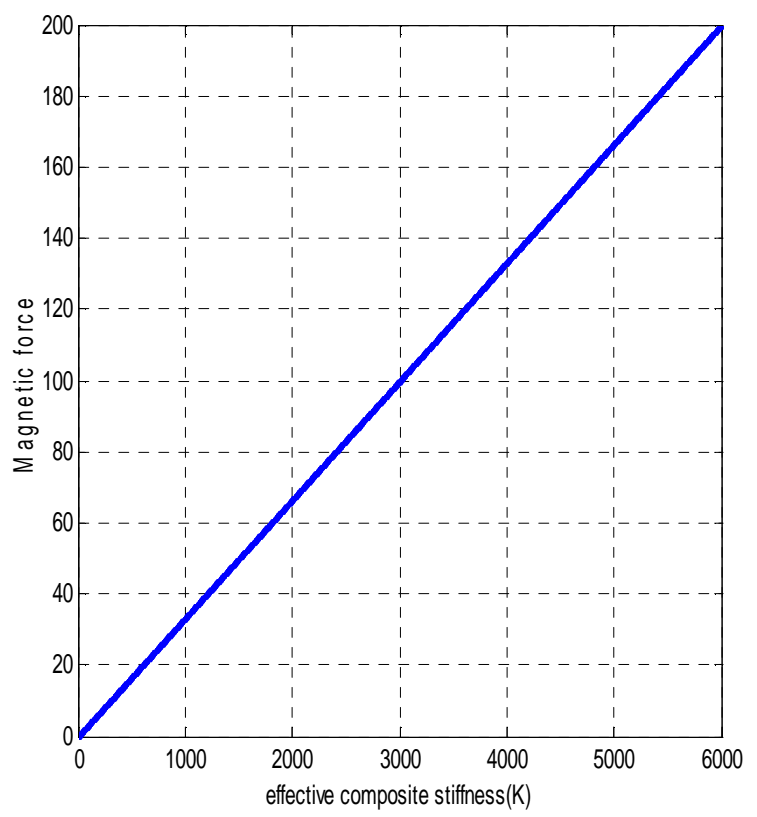

Fig:-5

Therefore finally the resultant magnetic force increases as compared to lateral force which can be written as:-(Fig:-5)

$$
R=\sqrt{\left(K / F_{m}\right)^{2}+\left(\mathbf{F}_{m}\right)^{2}}
$$

As per FEMA-356 drift values are limited to the following:

Table 1 Performance levels, corresponding damage state and drift limits

\begin{tabular}{|c|c|c|}
\hline Performance level & Damage state & Drift values \\
\hline Fully operational, Immediate occupancy (IO). & No damage & $<0.2 \%$ \\
\hline Operational, Damage control, Moderate & Repairable & $<0.5 \%$ \\
\hline Life safe - Damage state (LS) & Irreparable & $<1.5 \%$ \\
\hline Near collapse, Limited safety, Hazard reduced & Severe & $<2.5 \%$ \\
\hline Collapse prevention(CP) & & $>2.5 \%$ \\
\hline
\end{tabular}




\section{DESIGN STEPS}

Step 1: Take or choose target drift limit $\left(\theta_{\mathrm{d}}\right)$ for the structure as per FEMA- 356 depending on the type of building.

Step 2: Find the displacement at the critical storey $\left(\boldsymbol{\Delta}_{\mathbf{c}}\right)$ and also $\mathrm{m}_{\mathrm{e}}$ (effective mass), $\mathrm{H}_{\mathrm{e}}$ (height)etc.

$$
\Delta_{\mathbf{c}}=\theta_{\mathrm{d}} \mathrm{H}_{\mathrm{e}}
$$

Step 3: Find displacement $\left(\boldsymbol{\Delta}_{\mathbf{i}}\right)$ for different storey level corresponding their mode shapes or the relation given by J.D.Pettinga and M.J.N Priestley [6].

$$
\Delta_{\mathrm{i}}=\left(\boldsymbol{\Delta}_{\mathrm{c}} / \theta_{\mathrm{d}}\right) \cdot \theta_{\mathrm{i}}
$$

Step 4: Find equivalent displacement $\left(\boldsymbol{\Delta}_{\mathbf{d}}\right)$ for the critical storey level. Using the relation:

$$
\begin{gathered}
\sum_{i=1} \mathrm{~m}_{\mathrm{i}}^{\mathrm{n}} \boldsymbol{\Delta}_{\mathrm{i}}^{2} \\
\boldsymbol{\Delta}_{\mathrm{d}}={ }_{\mathrm{n}}^{\mathrm{n}} \\
\sum_{\mathrm{i}=\mathbf{1}} \mathrm{m}_{\mathrm{i}} \boldsymbol{\Delta}_{\mathrm{i}}
\end{gathered}
$$

Step 5: Find base shear force using the relation

$$
\mathrm{F}_{\mathrm{EQ}}=(\mathrm{Z} / 2)(\mathrm{I} / \mathrm{R})(\mathrm{Sa} / \mathrm{g}) \mathrm{W}
$$

Step 6: Find the dynamic stiffness $\mathrm{kq}=\mathrm{F}_{\mathrm{EQ}} / \boldsymbol{\Delta}_{\mathbf{d}}$.

Step 7: Computation also magnetic stiffness developed using, $\mathrm{k}_{\mathrm{m}}=\mathrm{F}_{\mathrm{m}} \boldsymbol{\Delta}_{\mathrm{d}}$.

Step 8: Find composite stiffness, $\mathrm{K}=\mathrm{kq} \mathrm{k}_{\mathrm{m}}$

Step 9: Computation of Resultant force using the relation

$$
R=\sqrt{\left(K / F_{m}\right)^{2}+\left(F_{m}\right)^{2}}
$$

Step 10: Similarly, Draw a graph of R vs. dynamic frictional coefficient (f) etc.

Step 11: Draw a graph of $\mathrm{R}$ vs. K etc

Step 12: Find the lateral resistance $\mathrm{F}_{\mathrm{EQ}}=(\mathrm{Z} / 2)(\mathrm{I} / \mathrm{R})(\mathrm{Sa} / \mathrm{g}) \mathrm{f}$ (W+R).

Step 13: Choose the value of ' $\mathrm{f}$ ' from the graph (R-f)

Step 14: Computation of effective stiffness $K_{e}=A_{h} f(R+W) / \Delta_{d}$.

Step 15: Computation of actual stiffness of structure $K=\omega^{2} \mathrm{~m}$

Step 16: Check $\mathrm{K}_{\mathrm{e}}>\mathrm{K}$ ok

Step 17: Find effective time period $T_{e}=2 \pi \sqrt{ } \mathrm{m}_{\mathrm{e}} / \mathrm{K}_{\mathrm{e}}$

Step 18: Computation of effective lateral resistance using

$$
\mathrm{F}_{\mathrm{E}}=\mathrm{m}_{\mathrm{e}}\left(4 \pi^{2} / \mathrm{T}_{\mathrm{e}}^{2}\right) \boldsymbol{\Delta}_{\mathbf{d}}
$$

Step 19: Check, $\mathrm{F}_{\mathrm{EQ}}<\mathrm{F}_{\mathrm{E}}$ ok, If not increase 'fm'

\section{CONSTRUCTION PROCEDURE OF ELECTROMAGNETIC SETUP: -}

For getting uniform magnetic field, the solenoid should be made cylindrical configuration and to increase the strength of electromagnet as per magnetic theory (Shown in Fig:-6), the following parameters should be increased:-

1. It depends on amount of current flow.

2. Number of turn in the coil.

3. Type of magnetic materials like iron, steel etc.

4. Electromagnetic setup should be made at the cg of the building where lumped mass is considered.

5. Electromagnetic setup should be made in series in different floors of the building.

6. Current should be passed in each solenoid in the different floors so that Produced North Pole (N) and South Pole(S) are maintained consecutively in series.

7. In this setup, electromagnet is to be put very close to the magnetic materials.

8. Magnetic materials should tightly be attached to the each floor with top and bottom faces.

\section{APPLICATION TECHNIQUE}

The device will be connected with power line and also with sensitive vibratory receiver in such a way that whenever earth shakes at the source, instantly, the sensitive device will receive the signal or a message that can also be send from seismograph station for a particular location and automatically, the receiver will operate power on and the device will produce magnetic field as well as magnetic force on the magnetic materials. So, this force in terms of stress will be transmitted to the each floors of the building and ultimately would produce the live load of the building or produce artificial weight of the structure which satisfies the criteria for isolation. 


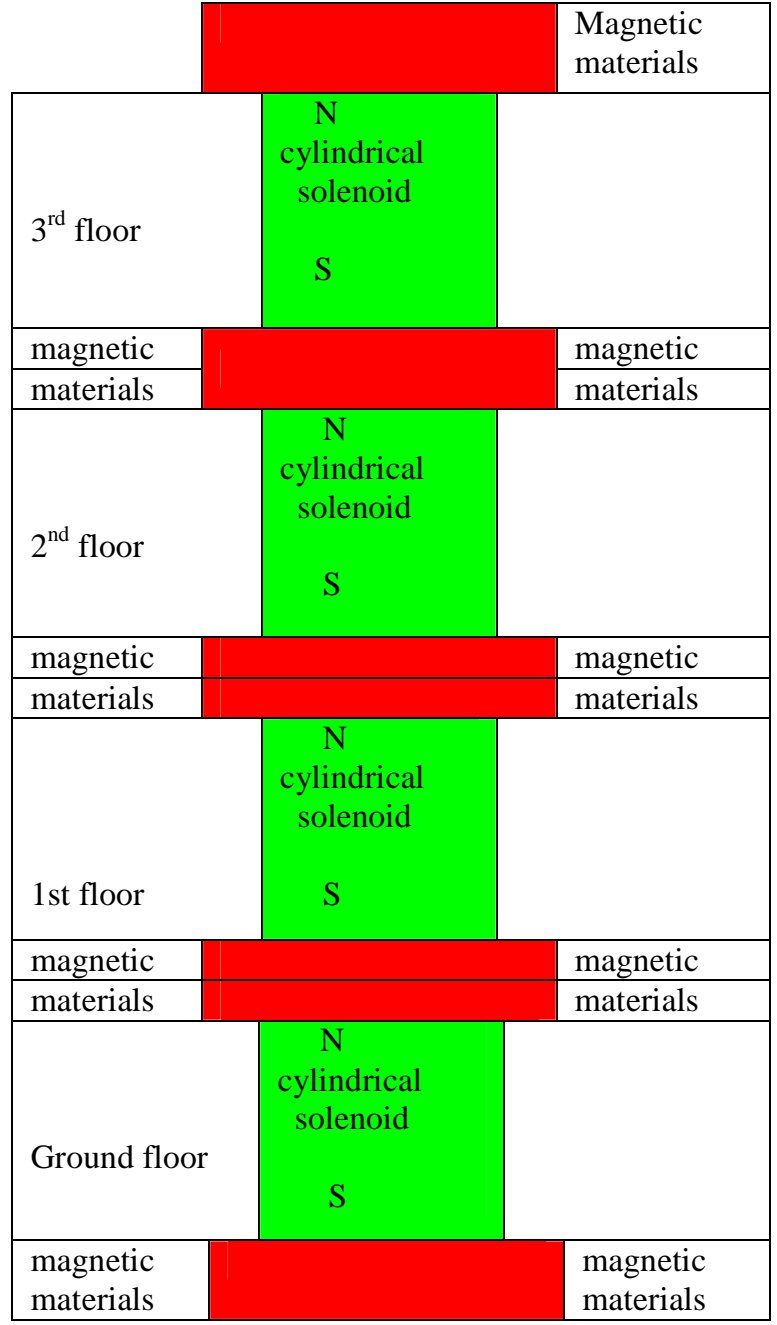

Fig:-6 Design of electromagnetic setup (device) is according to elevation of building

\section{CONCLUSIONS}

(1)Due to increase of magnetic force $\left(F_{m}\right)$, the lateral displacement $\left(\boldsymbol{\Delta}_{\mathbf{d}}\right)$ will decrease or we can say that, the lateral displacement will be towards to be a minimum value.

(2) This technique will be very useful in case of existing buildings which had been designed traditionally to be isolated easily and for which does not require any special retrofitting requirements to increase the lateral strength or stiffness of the structure. Therefore any building can be easily strengthened against the lateral force action etc.

(3)Design approach is a very simple procedure.

(4) In this procedure structural mass remain same or constant, but it increases the weight. or live load of structure which does not increase the seismic weight but increases the lateral resistance.

(5) If the higher earth quake comes more than the expected design level, in this situation also the structure can be strengthen by increasing the strength of electromagnet.

\section{REFFERENCES}

[1] C.M. Harris and A.G. Piersol,(2002) "Shock and Vibrations Handbook" McGraw Hill, New York

[2] Chopra A.K.(2007) "Dynamics of structures" prentice hall of India. New Delhi, India 